\title{
A study on air-sea interaction on the simulated seasonal climate in an ocean-atmosphere coupled model
}

\author{
Suryun Ham $\cdot$ Song-You Hong $\cdot$ Suhee Park
}

Received: 11 October 2012/ Accepted: 17 June 2013/Published online: 27 June 2013

(C) The Author(s) 2013. This article is published with open access at Springerlink.com

\begin{abstract}
This study investigates the effects of air-sea interaction upon simulated tropical climatology, focusing on the boreal summer mean precipitation and the embedded intra-seasonal oscillation (ISO) signal. Both the daily coupling of ocean-atmosphere and the diurnal variation of sea surface temperature (SST) at every time step by accounting for the ocean mixed layer and surface-energy budget at the ocean surface are considered. The oceanatmosphere coupled model component of the global/ regional integrated model system has been utilized. Results from the coupled model show better precipitation climatology than those from the atmosphere-only model, through the inclusion of SST-cloudiness-precipitation feedback in the coupled system. Cooling the ocean surface in the coupled model is mainly responsible for the improved precipitation climatology, whereas neither the coupling itself nor the diurnal variation in the SST influences the simulated climatology. However, the inclusion of the diurnal cycle in the SST shows a distinct improvement of the simulated ISO signal, by either decreasing or increasing the magnitude of spectral powers, as compared to the simulation results that exclude the diurnal variation of the SST in coupled models.
\end{abstract}

S. Ham · S.-Y. Hong

Department of Atmospheric Sciences, Yonsei University, Seoul, Korea

S.-Y. Hong ( $\bowtie)$

Department of Atmospheric Sciences, College of Science,

Yonsei University, Seoul 120-749, Korea

e-mail: songyouhong@gmail.com

S. Park

Climate Prediction Division, Korea Meteorological

Administration, Seoul, Korea
Keywords Intra-seasonal oscillation - Coupled climate model - Air-sea interaction - Diurnal variation of SST . GRIMs

\section{Introduction}

The tropical intraseasonal oscillation (ISO), also known as the Madden-Julian oscillation (MJO) is the dominant mode of low-frequency variability on a 30- to 60-day time scale in the tropical atmosphere. This signal is evident in largescale circulation, which is strongly coupled with fluctuations in convection originating in the Indian Ocean and moving eastward across the Maritime Continent into the western Pacific, and accounts for a large portion of the total variability in both large-scale circulation and convection over the tropical Eastern Hemisphere (Madden and Julian 1971, 1994; Rajendran and Kitoh 2006).

The ISO is important because of its considerable influence on monsoon dynamics, its generation of active and break phases of convection during the South-East Asian and Australian monsoons, its influence on general weather and climate variability, and because it is an important part of the ENSO cycle (Lau and Chan 1986; Kang et al. 1999; Hoyos and Webster 2007; Kim et al. 2010). During boreal summer, in addition to the eastward propagation, pronounced northward propagations of organized convection and associated large-scale circulation are evident over the Asian monsoon region (Yasunari 1981; Murakami and Nakazawa 1985; Srinivasan and Smith 1996). However, these phenomena are known to be difficult to capture in general circulation models (GCMs) (Hendon 2000; Zhang and Gottschalck 2002; Lin et al. 2006; Seo and Wang 2010).

There is growing interest in the role that air-sea interaction may play in the dynamics of the ISO. This interest is 
motivated by the fact that models with a prescribed sea surface temperature (SST) typically produce ISOs that move eastward too quickly, are too weak, and have incorrect seasonality (Slingo et al. 1996; Zheng et al. 2004; Fu et al. 2007; Kim and Kang 2008). Zheng et al. (2004) studied the role of coupled SSTs on the simulation of boreal winter and summer ISOs using the geophysical fluid dynamics laboratory (GFDL)-coupled GCM and demonstrated that the realistic phase relationship between SST and precipitation improved the simulation of ISOs in the coupled model. Kim and Kang (2008) suggested that higher temporal SST resolution improves the simulation and potential predictability of MJO characteristics including intensity and eastward propagation.

Many observational and modeling studies have shown that the ocean-atmosphere coupling is crucial to the maintenance of the ISO (Fu et al. 2004; Zheng et al. 2004; Rajendran and Kitoh 2006; Pegion and Kirtman 2008; Kim et al. 2010). Fu et al. (2004) showed that the ISO in an ocean-atmosphere coupled run is about $50 \%$ stronger than that in an atmosphere-only run. Rajendran and Kitoh (2006) suggested the presence of a dominant feedback mechanism between the ocean and the atmosphere, in which the ocean plays an important role in defining the ISO characteristics. Pegion and Kirtman (2008) showed that the overall intraseasonal variability of precipitation is reduced in the coupled simulation compared with the uncoupled simulation forced by daily SST. Kim et al. (2010) showed that the mean MJO intensity has more realistic amplitude in the coupled model than in the atmosphere-only model. These studies confirm that SSTs vary in response to changes in surface fluxes by intraseasonal variation in tropical convection, in the coupled model, and that the coupled model has the potential to reproduce observed aspects of ISOs.

Recently, it has been reported that the incorporation of diurnal variations of the SST into GCMs is also an important factor (Danabasoglu et al. 2006; Woolnough et al. 2007; Ham et al. 2010; Klingaman et al. 2011; Oh et al. 2013). Danabasoglu et al. (2006) suggested that the absence of the diurnal solar forcing of the ocean has several undesirable consequences in the coupled model, including excessive ENSO variability, significantly underestimated Pacific equatorial SST, and lack of deep-cycle turbulence. Woolnough et al. (2007) found that the improved representation of the diurnal variation is a significant factor in improving the MJO prediction skill. Ham et al. (2010) suggested that the implementation of the diurnal air-sea coupling strategy significantly reduced the cold temperature biases over equatorial western Pacific regions. Klingaman et al. (2011) found that the higher coupling frequency improves the MJO variability. Oh et al. (2013) found that suppressing the diurnal cycle shows a strong intraseasonal variability over the Maritime Continent. From these studies, it is clear that the inclusion of the diurnal cycle in coupling is important in either the simulated climatology or the MJO. However, a comprehensive evaluation of diurnal cycle in coupled model has not been carried out, due to the limitation of coupling frequency in previous studies.

In this study, the individual effect of the air-sea coupling due to SST changes, the coupling effect itself, and the diurnal variation of SST are isolated. The importance of each component in air-sea coupling will be investigated, and the results from the coupled model will be validated and compared with those of the atmosphere-only model. The coupled model used in this study is a newly developed GCM (Hong et al. 2013). The diurnal variation of SST is considered at every integration time step by the wind-driven mixed-layer cooling as well as the surface energy budget over the oceans in the atmosphere model component. The method of Kim and Hong (2010) that is applied to regional downscaling was adapted in this study, which can be a complementary solution to the coupled system on a daily basis. Simulations are conducted for boreal summers from 1997 to 2004 with a focus on evaluating the simulated precipitation climatology and the associated ISO.

This paper is organized as follows. The details of the model, experiments, and datasets are explained in Sect. 2. The effects of air-sea coupling, SST, and the diurnal cycle of SST on the tropical climate are discussed in Sect. 3. Finally, conclusion is presented in Sect. 4.

\section{Experimental design}

\subsection{Models}

The global ocean-atmosphere coupled model is a component of the recently developed the Global/Regional Integrated Model System (GRIMs) (Hong et al. 2013). The GRIMs was created for use in numerical weather prediction, seasonal simulations, and climate research projects over global to regional scales. In addition to the conventional spherical harmonics (SPH) dynamical core for the global model program (GMP), a double Fourier series (DFS, Cheong 2006) core is included as an alternative. A singlecolumn model (SCM) program was devised for effective evaluation of physics algorithms, and the aqua-planet was tested for the interaction of dynamics and physical parameterizations in atmospheric models. The regional model program with the scale selective spectral nudging (Hong and Chang 2012) has been applied to downscaling of climate changes. The history and configuration of the GRIMs and its capabilities in numerical weather prediction and climate simulations were demonstrated in Hong et al. (2013).

The atmospheric model utilized in the seasonal simulation employs a resolution of T62L28 (triangular 
truncation at wave number 62 in the horizontal and 28 terrain-following sigma layers in the vertical). We employ the GRIMs model physics version 3.1, which includes longwave and shortwave radiation (Chou et al. 1999; Chou and Suarez 1999; Chou et al. 2005), planetary boundarylayer processes (Hong et al. 2006), shallow convection (Hong et al. 2013), gravity-wave drag (Kim and Arakawa 1995; Chun and Baik 1998; Jeon et al. 2010), simple hydrology, and vertical and horizontal diffusion. For precipitation physics, stratiform precipitation processes (Hong et al. 1998) is employed in this model. Meanwhile, it has been reported that specific closures would improve the simulation of ISO in specific models. In this study, the simplified Arakawa-Schubert (SAS) scheme (Pan and Wu 1995; Hong and Pan 1998; Park and Hong 2007) is used in the model for cumulus convection scheme. The SAS scheme is based on the closure assumption of Arakawa and Schubert (1974), that is, the convective clouds stabilize the environment as fast as the convective processes destabilize it. The results regarding the sensitivity of the ISO to different convection schemes, using the coupled climate model, were discussed in Ham and Hong (2013).

The ocean model is the GFDL Modular Ocean Model version 3 (MOM3) (Pacanowski and Griffies 1998), which is a finite different version of the ocean primitive equations under the assumptions of Boussinesq and hydrostatic approximations. It uses spherical coordinates in the horizontal with a staggered Arakawa B grid and the $\mathrm{z}$ coordinate in the vertical. The domain is quasi-global, extending from $74^{\circ} \mathrm{S}$ to $64^{\circ} \mathrm{N}$. The zonal resolution is $1^{\circ}$. The meridional resolution is $1 / 3^{\circ}$ between $10^{\circ} \mathrm{S}$ and $10^{\circ} \mathrm{N}$, and gradually increases through the tropics until becoming fixed at $1^{\circ}$ poleward of $30^{\circ} \mathrm{S}$ and $30^{\circ} \mathrm{N}$. There are 40 layers in the vertical, 27 layers of which are in the uppermost $400 \mathrm{~m}$, and the bottom depth is around $4.5 \mathrm{~km}$. The vertical resolution is $10 \mathrm{~m}$ from the surface to a depth of $240 \mathrm{~m}$, and gradually increases to about $511 \mathrm{~m}$ in the bottom layer.

The atmospheric and oceanic components are coupled with no flux adjustment or correction. The two components exchange daily averaged quantities, such as heat and momentum fluxes, once a day. Because of the differences in the latitudinal domain, complete interaction between atmospheric and oceanic components is confined to $65^{\circ} \mathrm{S}$ to $50^{\circ} \mathrm{N}$. Poleward of $74^{\circ} \mathrm{S}$ and $64^{\circ} \mathrm{N}$, the SSTs needed for the atmospheric model are taken from observed climatology. Between $74^{\circ} \mathrm{S}$ and $65^{\circ} \mathrm{S}$ and between $64^{\circ} \mathrm{N}$ and $50^{\circ} \mathrm{N}$, SSTs for the atmospheric component are a weighted average of the observed climatology and the SST from the ocean component of the GRIMs.

The diurnal variation of SST considering the wind-driven mixed-layer cooling as well as the surface energy budget over the oceans is represented (Kim and Hong 2010). The ocean mixed layer (OML) depth is initialized to the global climatology field of the Naval Research Laboratory OML depth (Kara et al. 2003) every 0000 UTC. Kim and Hong (2010) showed that the inclusion of the ocean mixed-layer model cools the water surface due to enhanced mixing using the weather research and forecasting (WRF) model (Skamarock et al. 2008). They also suggested that cooling is largely compensated for by the inclusion of a prognostic skin temperature, since solar heating in the day time overwhelms cooling in the nighttime.

\subsection{Experiments}

Four experiments are designed, as summarized in Table 1. The AGCM experiment is the simulation with the atmospheric-only model. The CGCM experiment uses an atmosphere-ocean coupled model that couples on a daily basis. The diurnal variation of SST considering the winddriven mixed-layer cooling as well as surface energy budget over the oceans is taken into account. Two sensitivity experiments, the FSST and NODI experiments, examine the individual effects of coupling itself and the diurnal variation of SST. Because the FSST experiment is used the prescribed SST from the CGCM experiment, differences between the two experiments are due to the effects of air-sea coupling itself. Likewise, a comparison of the simulations from the NODI and CGCM experiments can help to understand the effect of diurnal variation of SST on the simulated summer climatology and ISO. All simulations are conducted for the eight extended boreal summers (May-June-July-August-September, MJJAS) from 1997 to 2004. Previous studies have showed that a 5-month period is sufficient to evaluate the characteristics of wave propagation and intensity of the ISO simulation (Park et al. 2010; Weaver et al. 2011).

The atmospheric initial conditions were derived from National Center for Environmental Prediction (NCEP)/ Department of Energy (DOE) Reanalysis-2 (RA2) data (Kanamitsu et al. 2002). As a surface boundary initial condition, observed SST data with a resolution of 1 degree were used (Reynolds and Smith, 1994). The ocean initial conditions were obtained from the Global Ocean Data Assimilation System (GODAS), which was made

Table 1 Summary of experiments designed in the atmosphere general circulation model and coupled atmosphere-ocean model frameworks

\begin{tabular}{ll}
\hline Exp. & Description \\
\hline AGCM & Atmosphere general circulation model with observed SST \\
CGCM & $\begin{array}{c}\text { Coupled atmosphere-ocean model with diurnal variation of } \\
\text { SST }\end{array}$ \\
FSST & AGCM with prescribed SST from CGCM \\
NODI & CGCM without diurnal variation of SST \\
\hline
\end{tabular}


operational at NCEP in September 2003. Simulated climatology including precipitation, large-scale features, and SST is evaluated against observed monthly and daily precipitation, and the observed large-scale fields, which are obtained from the Climate Prediction Center (CPC) Merged Analysis Monthly precipitation (CMAP) data (Xie and Arkin 1997), the Global Precipitation Climatology Project (GPCP) Satellite-Derived GOES precipitation index (GPI) daily Rainfall Estimates products (Huffman et al. 2001), RA2 data, an objectively analyzed air-sea fluxes (OAFlux) dataset for the global oceans ( $\mathrm{Yu}$ et al. 2004; Wu et al. 2007) and the optimally interpolated SST (OISST) data, respectively. The ability of the climate model to simulate the ISO is examined using a standardized set of diagnostics developed by the U.S. climate variability and predictability (CLIVAR) MJO Working Group. Detailed information regarding the diagnostics is available in Waliser et al. (2009).

\section{Results}

\subsection{Evaluation of the coupled climate model}

To review the performance of the GRIMs forecasts, SST, precipitation and large-scale features from the AGCM and CGCM experiments are first analyzed. Figure 1 shows the horizontal distribution of averaged SST fields for the eightyear period (1997-2004). The CGCM experiment shows an overall cooling over tropical Pacific, especially the western Pacific at around $20^{\circ} \mathrm{N}$. Furthermore, warming appears over the coastal region in the eastern Pacific. The cooling is due in part to the double inter-tropical convergence zone (ITCZ) problem, which is characterized by the significant SST bias in much of the tropical oceans and near the equator in both the Northern and Southern Hemispheres (Lin et al. 2007). Also, it is due to the increase of cloudiness and solar radiation blocking by air-sea interaction (Wu et al. 2007; Kug et al. 2008). This bias may reduce the benefits of the coupled model for predicting atmospheric variability.

Figure 2 exhibits the seasonal precipitation climatology from the AGCM and CGCM experiments. In comparison with the observed data, both runs satisfactorily reproduce the distribution of precipitation (Fig. 2a, b, c), but also show a double ITCZ pattern, which is a common problem seen in other GCMs (e.g., Covey et al. 2003; Dai 2006). Precipitation from the AGCM experiment tends to be exaggerated over the northwest and southwest Pacific and the Indian Ocean and underestimated over the western equatorial Pacific and the Bay of Bengal (Fig. 2d). Results from the coupled model show an improved tropical precipitation pattern by an increase in precipitation over the (a) OBS

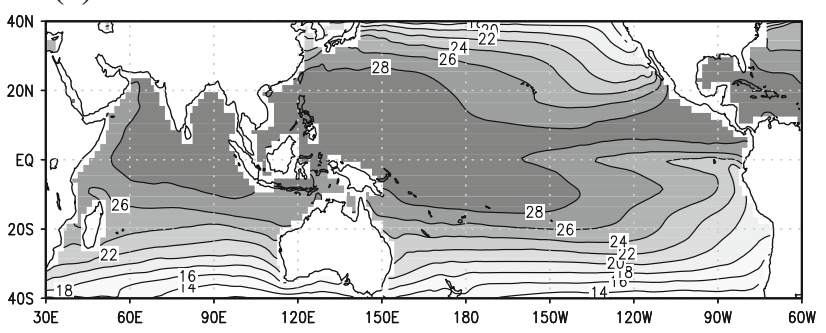

(b) CGCM

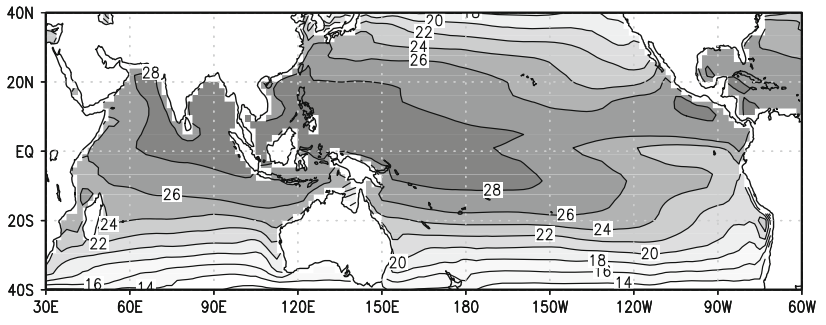

(c) $\mathrm{CGCM}$ - OBS

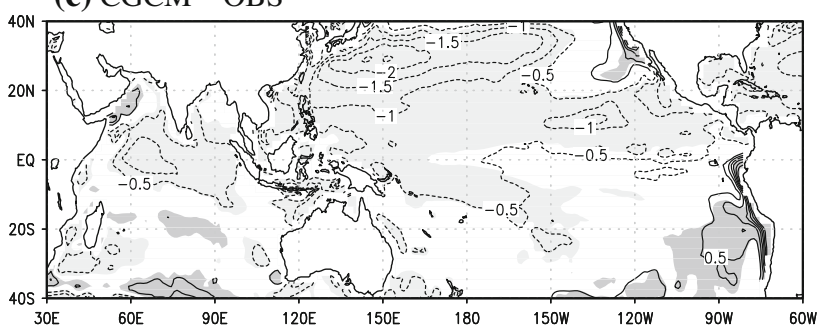

Fig. 1 May-September mean (a) Optimally interpolated sea surface temperature $\left({ }^{\circ} \mathrm{C}\right)$, (b) SST output from CGCM experiment, and (c) its differences. The period used in the calculation is 8 years (1997-2004). Shading region in (c) shows the $95 \%$ significance level. Dark (Light) shaded areas indicate positive (negative) differences

western equatorial Pacific and central tropical Pacific, and a reduction in the same over the Indian Ocean and the northwest and southwest Pacific. The CGCM experiment (0.76) shows a better correlation coefficient than the AGCM experiment (0.69). Nevertheless, the CGCM experiment gives a better climatology of precipitation and other atmospheric variables than the AGCM experiment, indicating that the effects of SST, air-sea coupling and diurnal variation of SST are critical to the correct simulation of the atmospheric climatology. The detail reasons are shown following figures.

Differences in the net surface heat fluxes between the AGCM experiment and OAFlux dataset, and between the AGCM and CGCM runs are shown in Fig. 3. Interestingly, the heat flux difference tends to be closely related to the precipitation bias pattern (see Figs. 2d, 3a). The wet bias can be linked to the negative heat flux difference by increased cloudiness and solar radiation blocking. The negative heat flux cools the ocean surface and induces 
(a) OBS

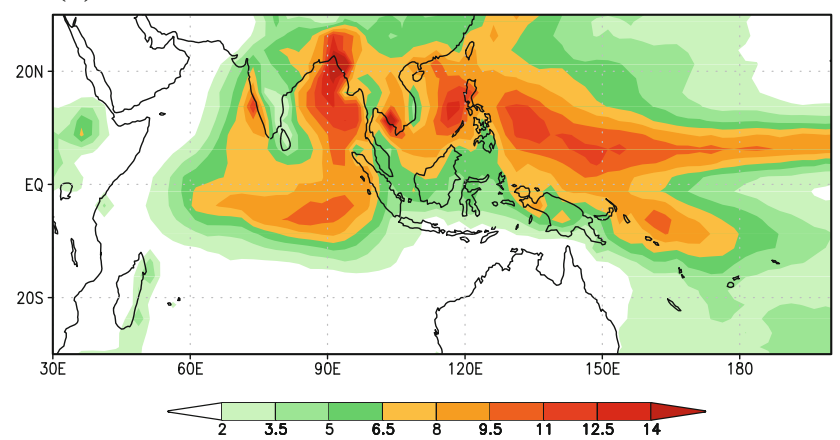

(b) $\operatorname{AGCM}(0.69)$

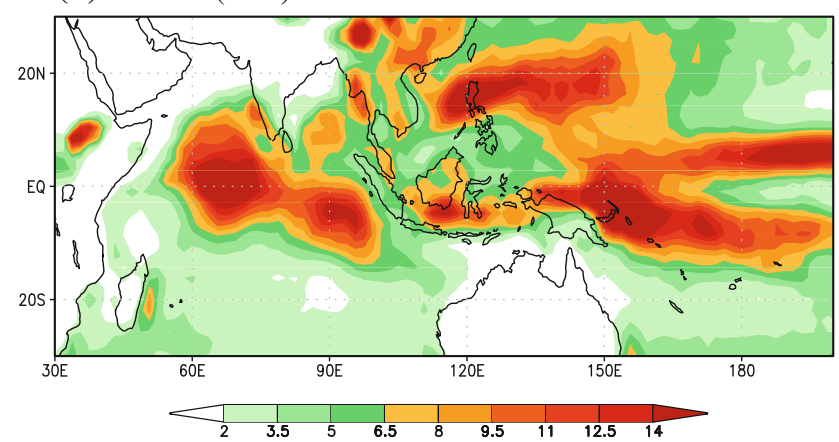

(d) AGCM - OBS

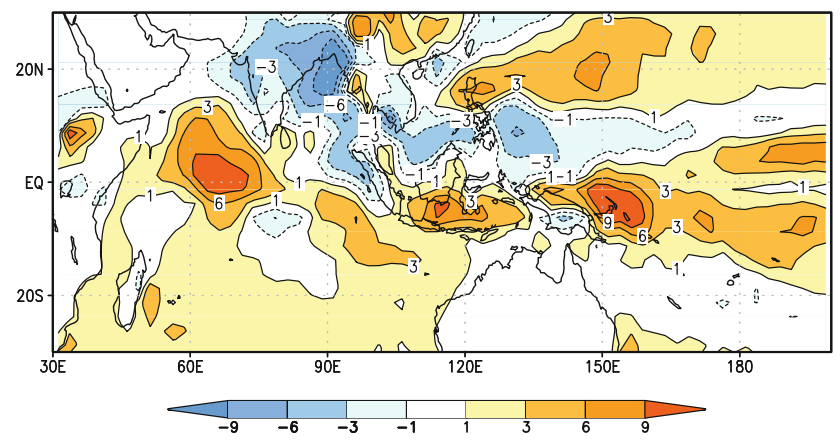

Fig. 2 a, b, c Seasonal mean distributions of precipitation (shading, $\mathrm{mm} \mathrm{day}{ }^{-1}$ ) averaged for the boreal summer (May-September) from 1997 to 2004. The values in the parentheses indicate the correlation coefficients between the CMAP and the simulated precipitation in the

additional SST cooling. However, the atmosphere-only model cannot reflect this process because it does not consider ocean-atmosphere interaction. In contrast to the atmosphere-only model, the coupled model includes the ocean-atmosphere feedback processes. Therefore, SST cooling in the coupled model leads to positive heat fluxes, which is related to the dry environment, whereas negative heat flux is related to an increase in precipitation. Although there are cooling biases in SST, the CGCM experiment shows improved precipitation simulation. This is due to the fact that the CGCM experiment includes the air-sea interaction such as SST-precipitation feedback. This result (c) $\operatorname{CGCM}(0.76)$

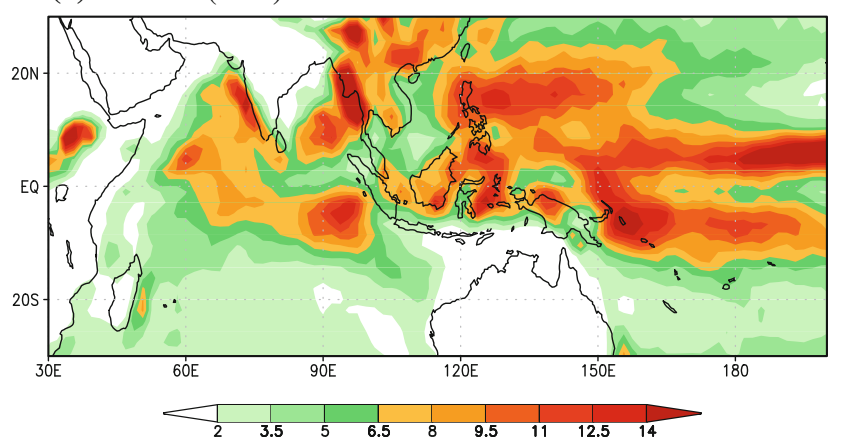

(e) $\mathrm{CGCM}$ - AGCM

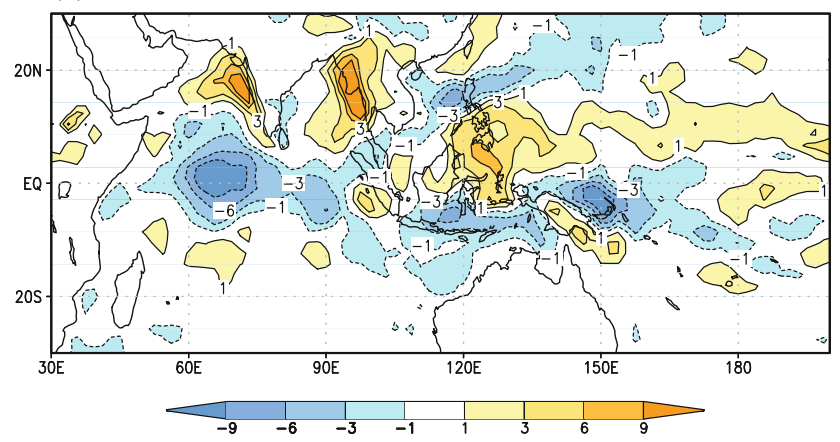

plotted region $\left(30^{\circ} \mathrm{S} \sim 30^{\circ} \mathrm{N}, 30^{\circ} \mathrm{E} \sim 160^{\circ} \mathrm{W}\right)$. Geographical distributions of difference in $\mathbf{d}$, e precipitation between the two experiments and observed data

is consistent in Kug et al. (2008) and Wu et al. (2007). Wu et al. (2007) also found that the AGCM simulation leads to excessively large seasonal mean rainfall and surface latent heat fluxes anomalies.

Which factors play a role in the correct simulation of atmospheric climatology? Figure 4 shows the horizontal difference distribution of precipitation. Effect of SST itself (i.e., FSST-AGCM) leads to an increase in precipitation over the western Pacific, equatorial Pacific, and the Bay of Bengal, and a decrease in precipitation over the Indian Ocean and sub-tropical Pacific (Fig. 4a). By air-sea coupling effects (i.e., CGCM-FSST), rainfall is a little 
(a) NET SFC HEAT FLUX (AGCM - OBS)

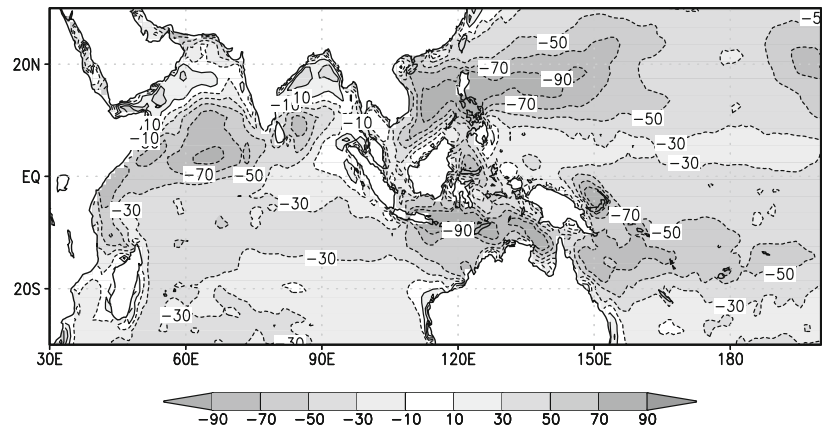

(b) NET SFC HEAT FLUX (CGCM - AGCM)

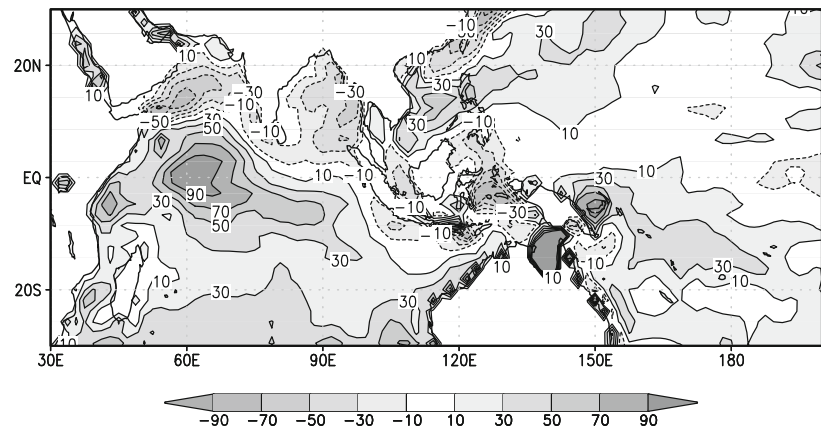

Fig. 3 a Climatological biases of net surface heat flux in the AGCM experiment and OAFlux dataset, $\mathbf{b}$ difference fields between the CGCM and AGCM experiments. Unit is $\mathrm{W} \mathrm{m}^{-2}$

decreased over the tropical Pacific (Fig. 4b). The diurnal variation of SST (i.e., CGCM-NODI) drives a slight change in precipitation over the Indian Ocean and the western and central Pacific (Fig. 4c). Thus, it is clear that the SST change is the major cause for the improve precipitation climatology. Either the coupling itself or inclusion of diurnal variation in SST does not affect significantly the simulated precipitation climatology.

The difference fields of the net surface heat fluxes between the experiments are shown in Fig. 5. Just like a precipitation, net surface heat flux is significantly changed by effects of SST. Although the coupling itself does not affect the simulated precipitation climatology, net surface heat flux from the CGCM experiment are enhanced compare to that from the FSST experiment, although both experiments have the same SST. The effects of diurnal variation of SST are not dominant in controlling surface fluxes and precipitation. Thus, it is clear that the improvement in the overall precipitation pattern in the CGCM experiment is due to the effect of SST with consideration of ocean-atmosphere feedback. (a) Precipitation (FSST -AGCM)

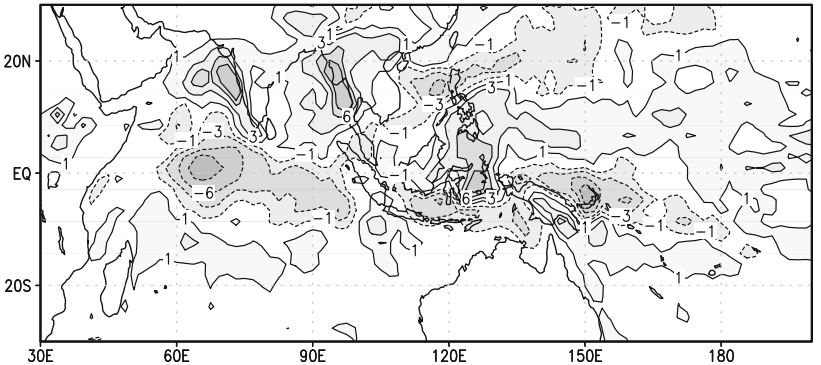

(b) Precipitation (CGCM - FSST)

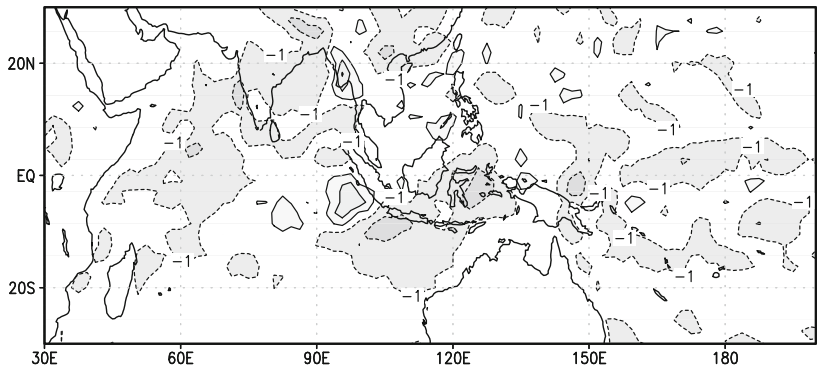

(c) Precipitation (CGCM - NODI)

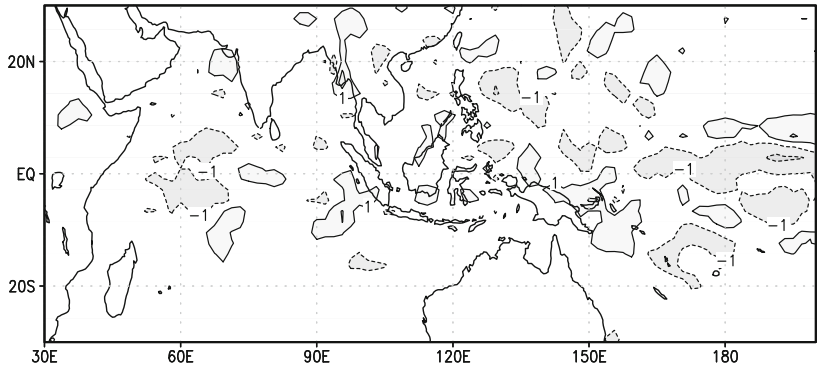

Fig. 4 May-September mean precipitation $\left(\mathrm{mm} \mathrm{day}^{-1}\right)$ difference fields between the a FSST and AGCM, b CGCM and FSST, $\mathbf{c}$ CGCM and NODI experiments. The period used in the calculation is 8 years (1997-2004)

This improvement by coupling can be quantitatively visualized in the Taylor diagram (Fig. 6). The correlation coefficients from the CGCM and FSST experiments show higher pattern correlation coefficients than that from the AGCM experiment. The correlation coefficient and root mean square error from the NODI experiment are similar to those from the CGCM experiment, but with a reduction of standard deviation. Consequently, the change in SST due to coupling is the major cause for the improved precipitation climatology. Either the coupling itself or the inclusion of diurnal variation in SST does not affect the simulated precipitation climatology. 
(a) NET SFC HEAT FLUX (FSST - AGCM)

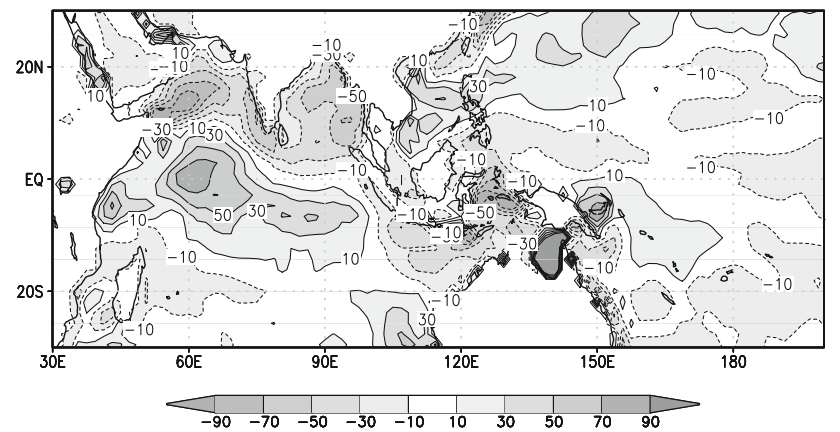

(b) NET SFC HEAT FLUX (CGCM - FSST)

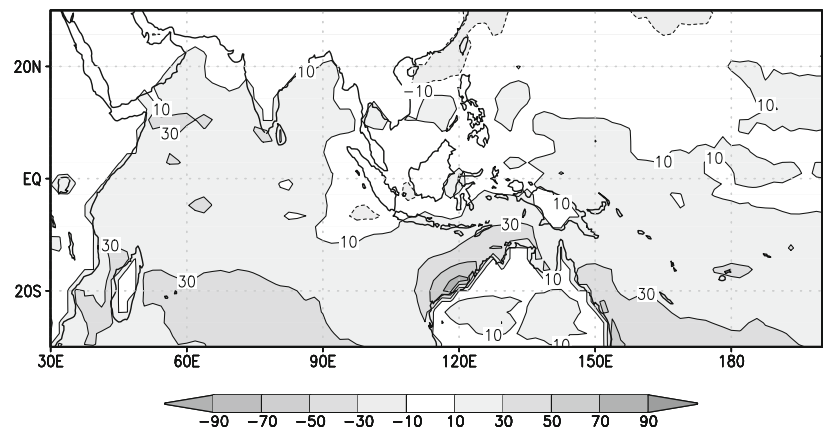

(c) NET SFC HEAT FLUX (CGCM - NODI)

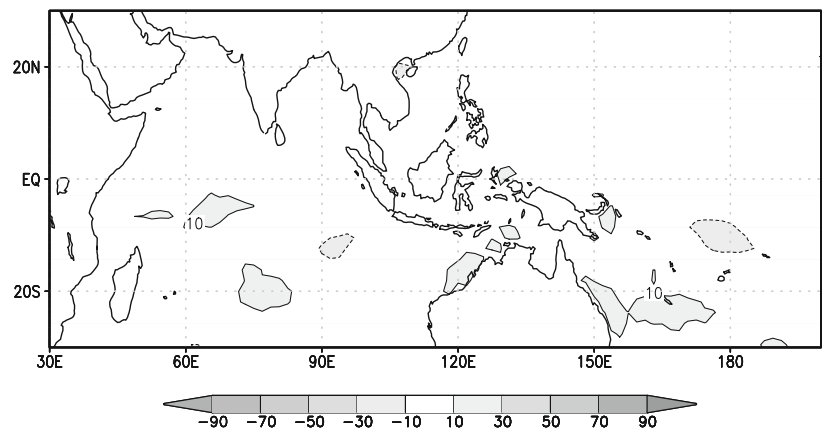

Fig. 5 Net surface heat flux difference fields between the a FSST and AGCM, b CGCM and FSST, $\mathbf{c}$ CGCM and NODI experiments. Unit is $\mathrm{W} \mathrm{m}^{-2}$

\subsection{Evaluation of ISO}

To demonstrate how the magnitude and geographical distribution of intraseasonal variability are simulated, maps of the 20-100-day filtered variances of precipitation are shown in Fig. 7. In observation, the precipitation variance maximum is located in the eastern Indian Ocean and western Pacific (Fig. 7a). Overall, all simulations show similar patterns in terms of dominant variance over the Indian Ocean and the western and eastern Pacific compared to those from the GPCP observations. It is clear that the AGCM experiment exaggerates the variance along the

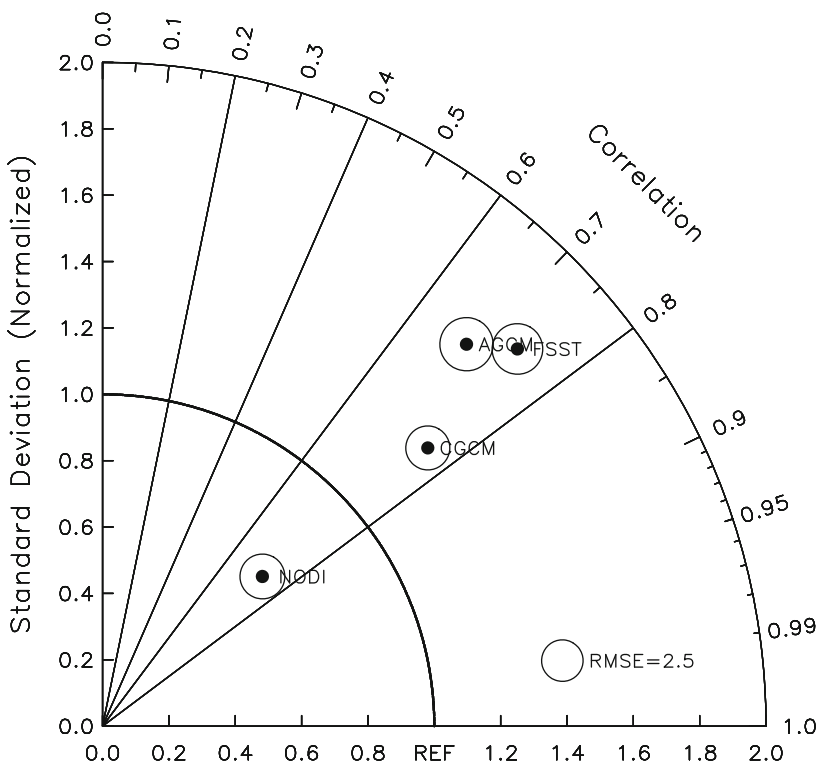

Fig. 6 Taylor diagram of standard deviation and pattern correlation coefficient for summer precipitation. The size of each circle indicates the magnitudes of root mean square errors

ITCZ over the central and eastern Pacific, Indian Ocean, and the South Pacific Convergence Zone (SPCZ) over the western Pacific (Fig. 7b). The CGCM, FSST, and NODI experiments also overestimated the variance, but to a lesser extent than the AGCM experiment (Fig. 7c, e, f). Results from the FSST and NODI experiments are similar to those from the CGCM run. The variance in the CGCM experiment is the closest to that observed over the northwest Pacific and Indian Ocean. The pattern correlation coefficient from the CGCM is 0.66 , which is the highest of all the experiments.

Equatorial wavenumber-frequency spectra (Hayashi 1979) for equatorial $850-\mathrm{hPa}$ zonal wind to the isolation of the characteristic spatial and temporal scales on which variability is organized are shown in Fig. 8. The zonal wind was chosen for the analysis of the ISO signal because it is important to the ISO surface energy budget, with implications for air-sea interactions and wind-induced flux forcing of convection (e.g., Hendon 2000; Inness et al. 2003; Bellon et al. 2008. The spectra were computed by Fourier transforming 180-day segments centered on the boreal summer, forming power, and then averaging over 8 years of data (1997-2004). The resulting bandwidth is $(180 \text { days })^{-1}$. By definition, eastward propagation is represented by positive frequency and positive wavenumber, whereas westward propagation is represented by one or the other being negative. If standing oscillations are present, they will project as equal amounts of power in the eastward and westward directions. 
(a) GPCP

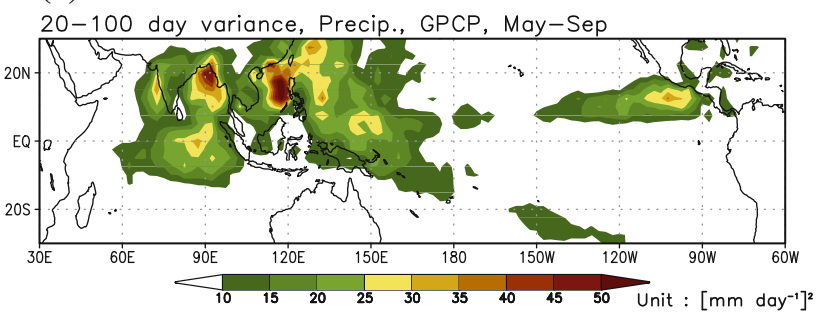

(b) AGCM (0.60)

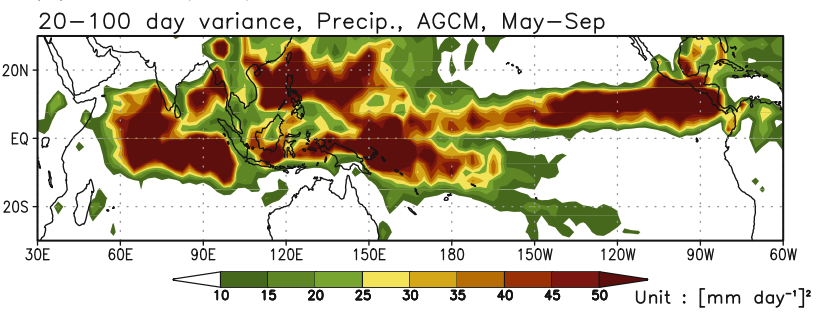

(c) CGCM (0.66)

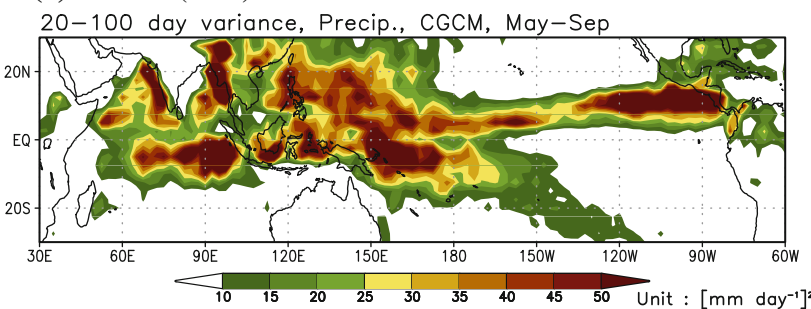

(d) $\operatorname{FSST}(0.63)$

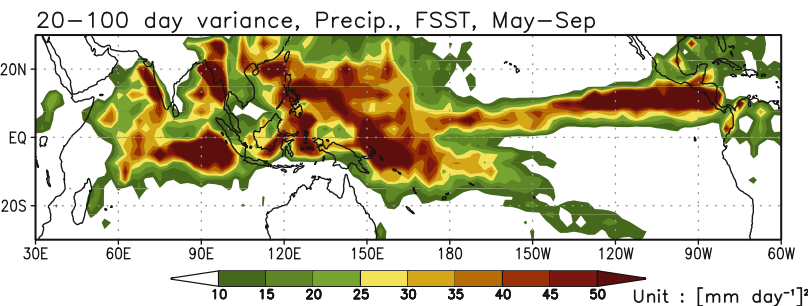

(e) NODI (0.65)

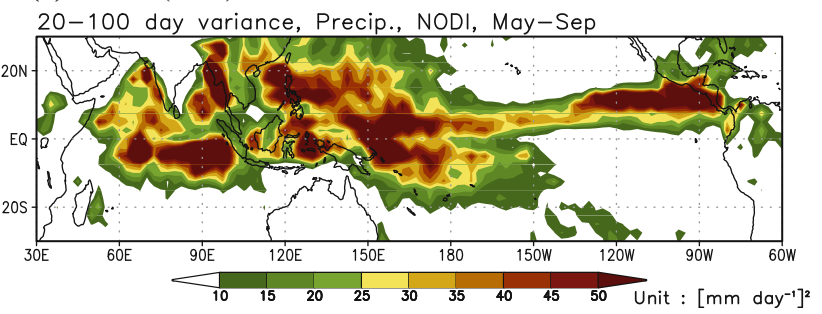

Fig. 7 The 20- to 100-day precipitation variance $\left(\mathrm{mm}^{2} \mathrm{day}^{-2}\right)$ averaged for the 8-year from 1997 to 2004. a GPCP observation, b AGCM, c CGCM, d FSST, and e NODI experiment, respectively. The values in the parentheses indicate the correlation coefficients between the GPCP data and simulated precipitation variance in the plotted region $\left(30^{\circ} \mathrm{S}-30^{\circ} \mathrm{N}, 30^{\circ} \mathrm{E}-60^{\circ} \mathrm{W}\right)$
Consistent with the results of previous studies (Lawrence and Webster 2002; Wheeler and Hendon 2004; Zhang et al. 2006; Kim et al. 2009), the dominant spatial scale of the $850-\mathrm{hPa}$ zonal wind in observations is zonal wavenumber 1 for periods of 30-80 days (Fig. 8a). The eastward power is about four times that of the westward power at intraseasonal frequencies and spatial scales characteristic of the ISO. All experiments reproduce a spectrum with wavenumber 1 , which is similar to the observed spectra. For most experiments, eastward propagating power tends to be concentrated at low frequency (period >80 days). The simulated power from AGCM experiment shows a more exaggerated magnitude than the other results (Fig. 8b). Meanwhile, the wavenumber spectra in the eastward and westward directions for the FSST, NODI, and CGCM experiment are similar to each other (Fig. 8c, d, e).

To assess whether the extracted ISO modes are physically meaningful and distinct from a red noise process, the power spectra of an unfiltered $850-\mathrm{hPa}$ zonal wind was calculated over the Indian Ocean $\left(68.75^{\circ} \mathrm{E}-96.25^{\circ} \mathrm{E}\right.$, $3.75^{\circ} \mathrm{N}-21.25^{\circ} \mathrm{N}$ ) from the RA2 data and model simulations (Fig. 9). In the RA2 data, the spectral power that is statistically significant at the $95 \%$ confidence level, relative to a red noise process, is concentrated near a period of 50 days and related to the ISO modes (Fig. 9a). The AGCM simulation also shows the power to be statistically significant near a period of 50 days; however its magnitude is too weak (Fig. 9b). The CGCM experiment well captures the power near a period of 60 and 20 days as seen in the RA2 data (Fig. 9c). In the FSST experiment, the period related to the ISO signal is near the ISO time scale; however, the power is concentrated at low frequencies (period $>80$ days) (Fig. 9d). The NODI experiment shows the period of 60 and 20 days as seen in the CGCM experiment; however, the magnitude is exaggerated (Fig. 9e). Therefore, it is clear that the simulation of ISO phases can be improved by the inclusion of diurnal variation in SST. From Table 2, which is tabulated the frequency and power at 1 st and 2 nd peak as seen in the RA2 data, it is also confirmed that the magnitudes of 1st and 2nd power from CGCM experiment $(0.021,0.019)$ show the closest to those from the RA2 data $(0.018,0.019)$.

To further examine the effect of diurnal cycle in SST on the simulated ISO, the additional experiments with a doubled resolution at the triangular truncation at wave number 126 in the horizontal were performed for the NODI and CGCM experiments. In Fig. 10, it is seen that the period related to the ISO signal is near the ISO time scale (about 60 days) when the diurnal cycle is 
(a) RA2

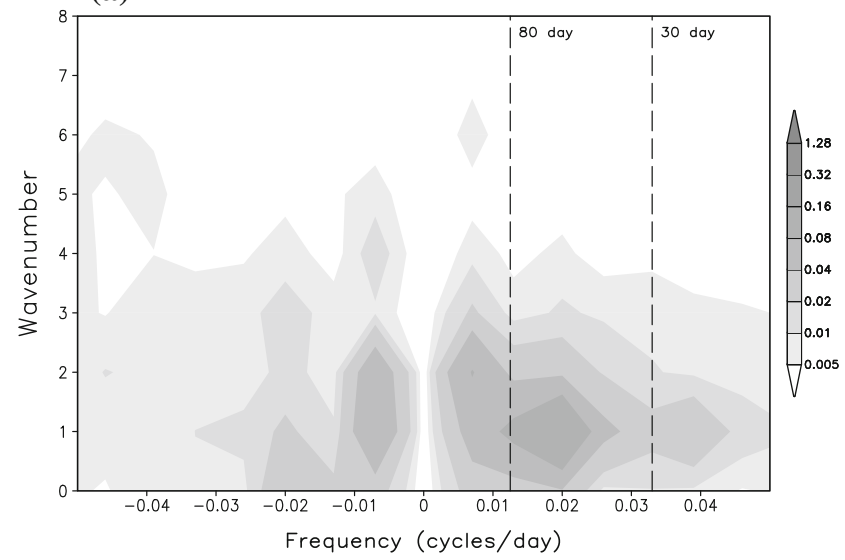

(b) AGCM

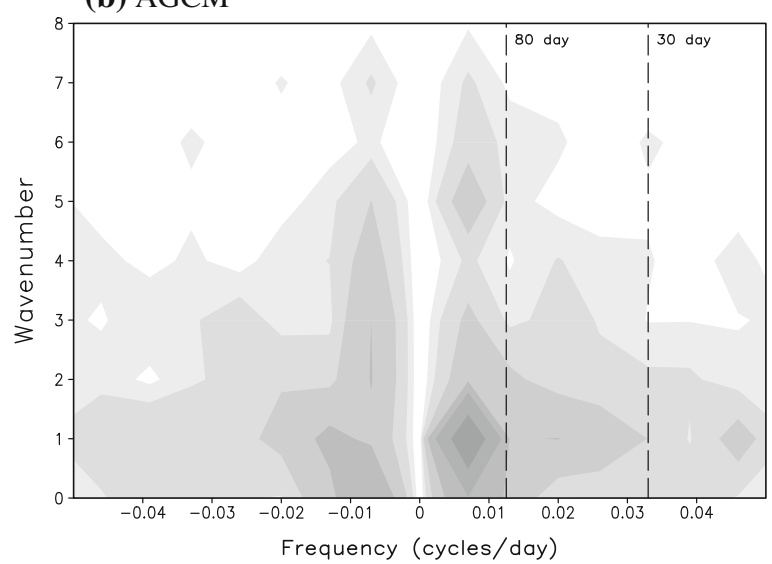

(d) FSST

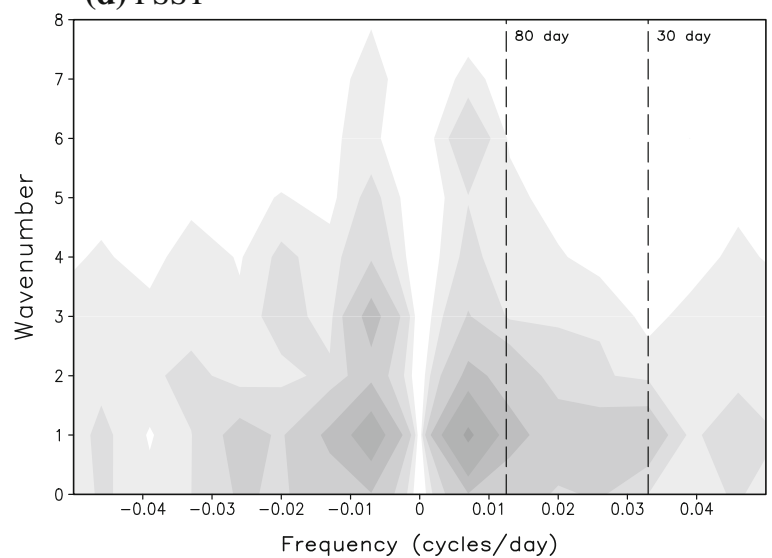

Fig. 8 May-September wavenumber-frequency spectra of $10^{\circ} \mathrm{N}-$ $10^{\circ} \mathrm{S}$ averaged $850-\mathrm{hPa}$ zonal wind $\left(\mathrm{m}^{2} \mathrm{~s}^{-2}\right)$ for the a NCEP/NCAR reanalysis-data, b AGCM, c CGCM, d FSST, and e NODI experiment, respectively. Individual May-September spectra were

considered. The power near the period of 20 days is reduced towards the observed. It is noted that results from the NODI experiment show a weakened power near the period of 60 days and exaggerated power near the period of 20 days. This finding demonstrates that the inclusion of (c) $\mathrm{CGCM}$

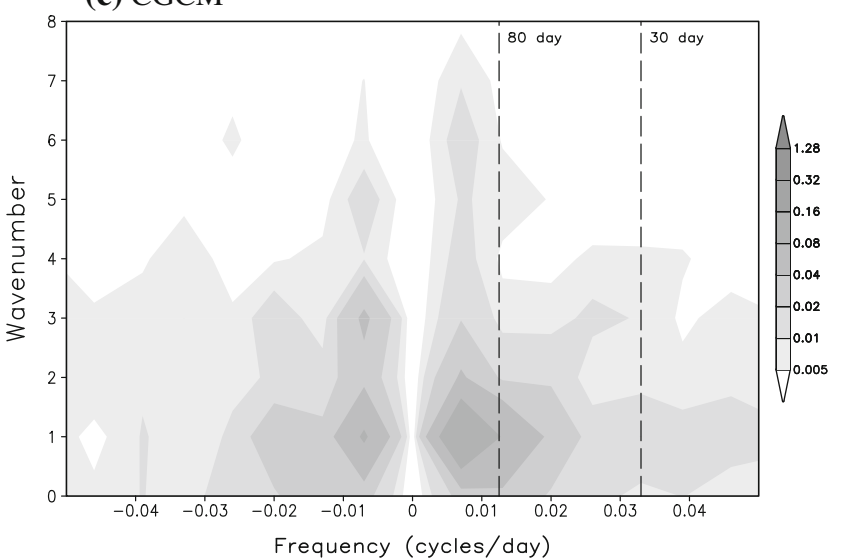

(e) NODI

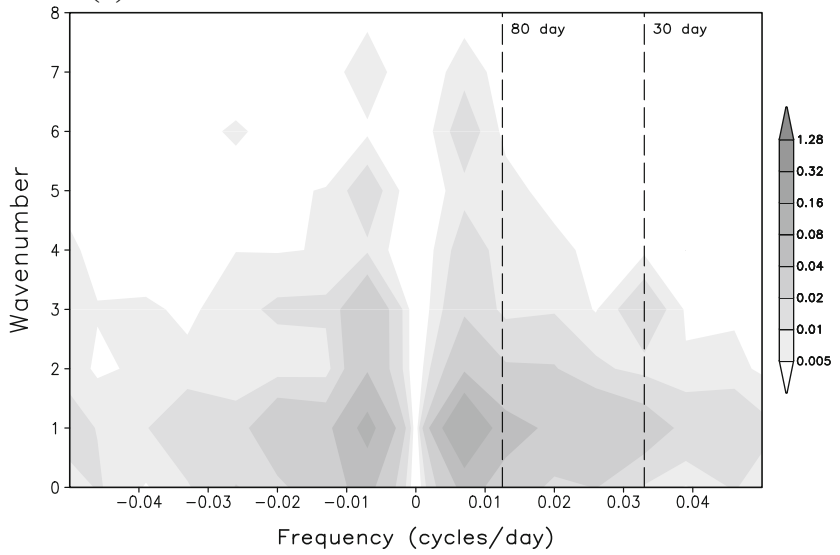

calculated for each year and then averaged over all years of data. Only the climatological seasonal cycle and time mean for each MaySeptember segment were removed before calculation of the spectra. The bandwidth is $(180 \text { days })^{-1}$

diurnal cycle in SST consistently improves the magnitude of ISO by suppressing or enhancing the magnitude of the power spectra.

Consequently, using prescribed SST from coupled model in the atmosphere-only model leads to the improved 
(a) RA2

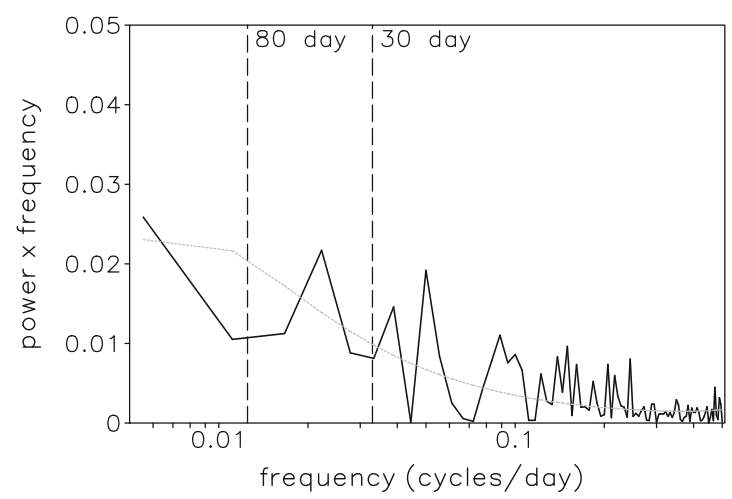

(b) AGCM

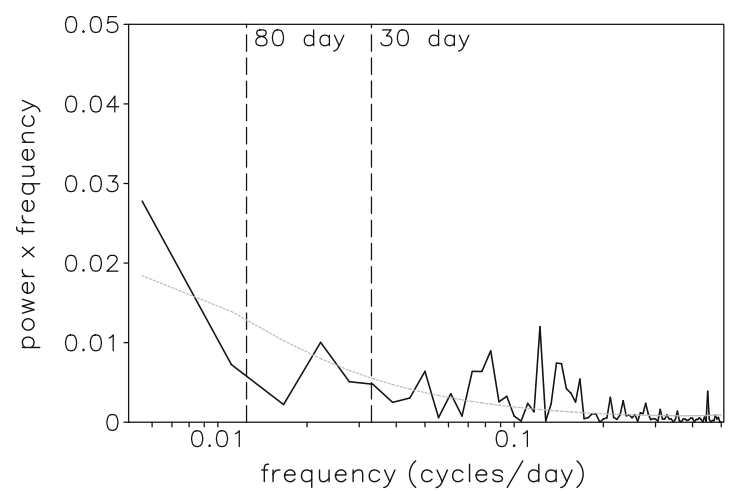

(d) FSST

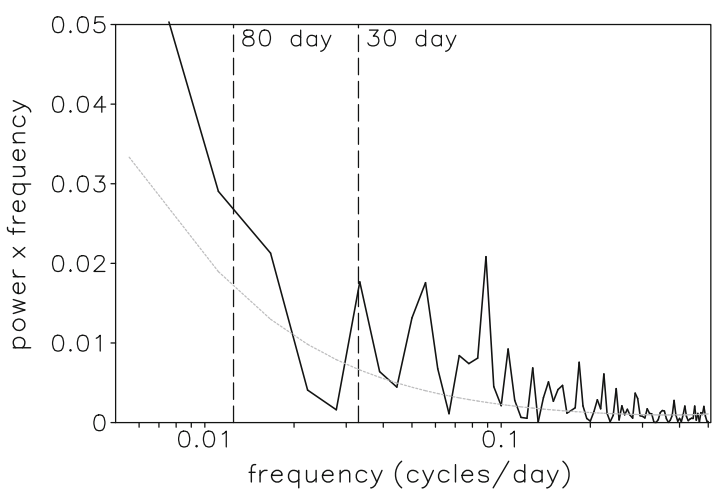

Fig. 9 The power spectrum of daily $850-\mathrm{hPa}$ zonal winds anomaly for the boreal summers from 1997 to 2004 . $850-\mathrm{hPa}$ zonal winds are area averaged over the domain of $3.75^{\circ} \mathrm{N}-21.25^{\circ} \mathrm{N}$ and $68.75^{\circ} \mathrm{E}-$

prediction of large-scale fields and precipitation. Also, the coupling itself does not affect the simulated precipitation climatology. Although the diurnal variation of SST does not provide a significant effect on seasonal tropical pre- (c) $\mathrm{CGCM}$

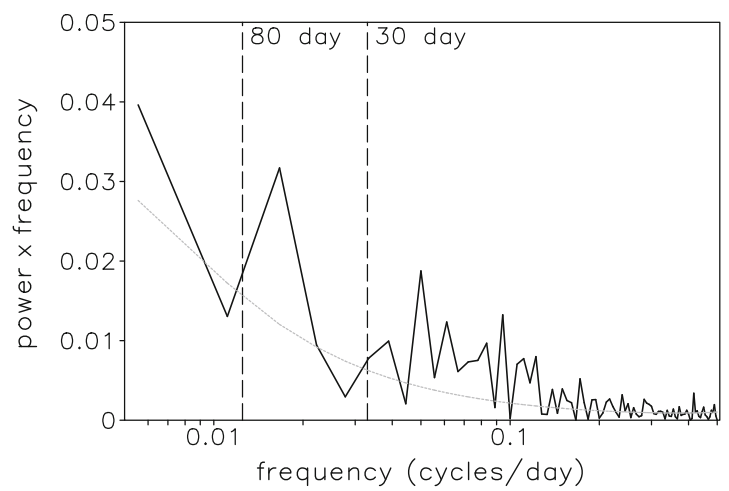

(e) NODI

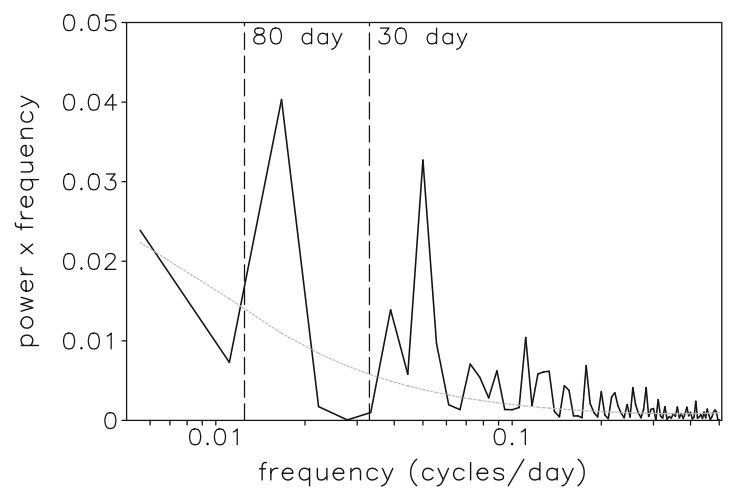

$96.25^{\circ} \mathrm{E}$ (Indian Ocean). Dotted lines show the upper $95 \%$ confidence limits on this red noise spectrum

cipitation climatology, the ISO simulation is modulated to some extent since the frequency and power from the CGCM experiment are better reproduced than those from the NODI experiment. 
Table 2 Frequency (cycles day ${ }^{-1}$ ) and power at 1 st and 2 nd peak in the power spectrum of daily $850-\mathrm{hPa}$ zonal winds anomaly for the boreal summers from 1997 to 2004

\begin{tabular}{llllll}
\hline Exp. & \multicolumn{1}{l}{ 1st peak } & & & 2nd peak \\
\cline { 2 - 3 } \cline { 6 - 6 } & Frequency & Power & & Frequency & Power \\
\hline RA2 & 0.022 & 0.021 & & 0.050 & 0.019 \\
AGCM & 0.022 & 0.010 & & 0.120 & 0.012 \\
CGCM & 0.018 & 0.031 & & 0.050 & 0.019 \\
FSST & 0.030 & 0.019 & & 0.090 & 0.021 \\
NODI & 0.018 & 0.040 & & 0.052 & 0.032 \\
\hline
\end{tabular}

(a) NODI

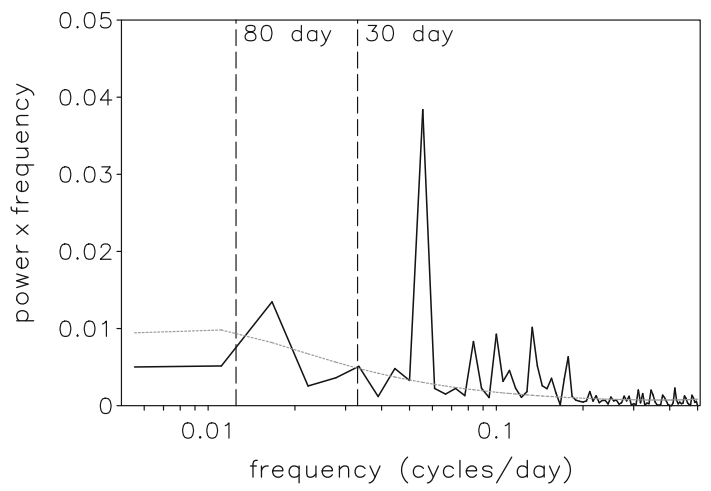

(b) CGCM

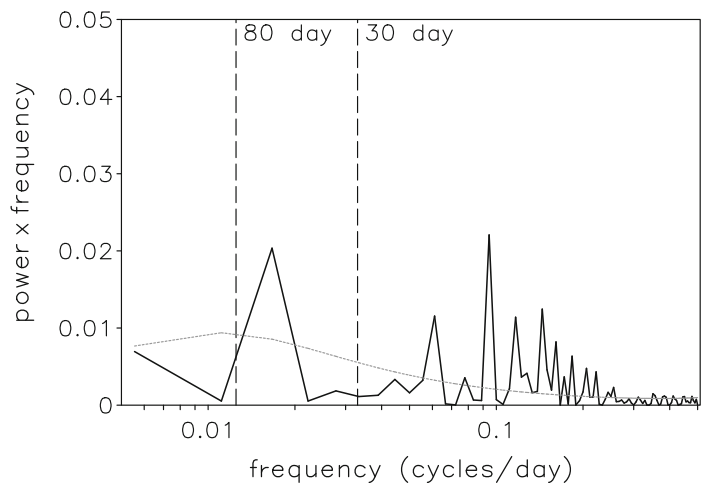

Fig. 10 Same as in Fig. 9, but for a NODI, b CGCM experiments with high resolutions

\section{Concluding remarks}

In this study, we investigate the impacts of air-sea interaction on simulated tropical climatology using the atmosphere-only model and atmosphere-ocean coupled model. Two sensitivity experiments examine the individual effects of coupling process and the diurnal variation of SST. The characteristics of wave propagation and the intensity of the ISO simulated by the model, together with the mean climatology, are investigated for extended boreal summers from 1997 to 2004.
The coupled run satisfactorily reproduces the distribution of SST compared with the observed data; however it shows cold biases over the tropical Pacific region. In the coupled model included all effects (SST changes, coupling, and diurnal variation of SST), the precipitation pattern shows better agreement with the observed data than that from the atmospheric run. It is due to the fact that the coupled run can reflect the SST cooling by interaction of positive heat flux related to the decreased precipitation. Consequently, the SST change due to coupling is the major cause of the improved precipitation climatology. Either the coupling itself or the inclusion of diurnal variation in SST does not affect significantly the simulated precipitation climatology. These results can confirm in the Taylor diagram of standard deviation and pattern correlation coefficient for precipitation.

All experiments exaggerate the variance along the ITCZ over the central and eastern Pacific, the Indian Ocean and the SPCZ over the western Pacific. The variance from the coupled model is closer to that observed along the ITCZ and SPCZ; however, it is still exaggerated over a broader region. In the RA2 $850 \mathrm{hPa}$ zonal wind data, the spectral power is concentrated near a period of 50 days. In the atmospheric run, the power is similar to the RA2 data; however, the magnitude is too weak. The coupled run shows the reasonable periods and magnitude of spectral power.

Meanwhile, Fu et al. (2004) showed that when initial conditions and SST forcing are exactly the same for coupled run and atmospheric run, identical ISO solutions are found for both of them. Our study identified the differences in ISO power spectrum for the two experiments, even if the AGCM utilizes the same initial conditions and SST output from the coupled run. It is due to the addition of diurnal cycle in the coupled run through the mixed layer cooling and surface energy budget that are computed every integration time step. Additional experiment that excludes the diurnal cycle in coupled run further confirms the importance of diurnal cycle in SST variation by decreasing or increasing the magnitude of spectral power.

Also, some studies have demonstrated that air-sea coupling does not appear to be critical for ISO or using a coupled model did not give definitively accurate ISO simulation (Hendon 2000; Zhang et al. 2006; Newman 2007). Hendon (2000) demonstrated that coupling is not a panacea for problems of simulating the MJO in uncoupled GCM by investigation of tropical MJO with an atmospheric model coupled OML model. Zhang et al. (2006) found that air-sea coupling generally strengthens the simulated eastward propagating signal, but its effects are inconsistent among the simulations. Newman (2007) investigated understanding of tropical decadal variability using some coupled models. They demonstrated that stationary eigenmode is not captured well in many coupled GCMs because the tropical SST decadal variability from many coupled 
GCMs is still too weak and North Pacific SSTs are too independent of the Tropics.

Meanwhile, a number of studies (Fu et al. 2003; Zheng et al. 2004; Wu et al. 2007; Kug et al. 2008; Pegion and Kirtman 2008; Kim et al. 2010; Watterson 2013; Watterson and O'Farrell 2013) as well as this study suggested that the feedback between the ocean and atmosphere plays an important role in climatological simulation and defining the ISO characteristics. For example, Kim et al. (2010) showed that the mean MJO intensity has more realistic amplitude in the coupled model than in the atmosphere-only model. Wu et al. (2007) and Kug et al. (2008) suggested that SST-precipitation feedback in coupled model leads to improve the simulated precipitation climatology, although much work remains to improve the $\mathrm{MJO}$ in climate models despite improvement in representing ISO in coupled models (Zhang 2005; Sperber and Annamalai 2008). These results are consistent in our study.

Our study implies that the effects of the diurnal variation of SST should be taken into account when simulating ISO in coupled GCMs. The coupled run improves the simulated climatology as well. A link between the seasonal climatology and ISO is a debating issue, even though there is some evidence between them. For example, Park et al. (2010) demonstrated that accurate ISO simulation contributes to the improved seasonal predictability of boreal summer precipitation. Kumar et al. (2010) showed an inverse relationship with rainfall over India and ISO index. Further understanding of feedback mechanism between seasonal prediction and ISO is to needed.

Acknowledgments This work was supported by the Basic Science Research Program through the National Research Foundation of Korea (NRF) funded by the Ministry of Education, Science and Technology (2012-0000158) and also funded by Korea Meteorological Administration Research and Development Program under Grant CATER 2012-3084. The authors would like to acknowledge the support from KISTI supercomputing center through the strategic support program for the supercomputing application research [No. KSC-2011-C3-11].

Open Access This article is distributed under the terms of the Creative Commons Attribution License which permits any use, distribution, and reproduction in any medium, provided the original author(s) and the source are credited.

\section{References}

Arakawa A, Schubert WH (1974) Interaction of a cumulus cloud ensemble with the large scale environment. Part I. J Atmos Sci 31:674-701

Bellon B, Sobel A, Vialard JP (2008) Ocean-atmosphere coupling in the monsoon intraseasonal oscillation: a simple model study. J Clim 21:5254-5270

Cheong H-B (2006) A dynamical core with double fourier series: comparison with spherical harmonics method. Mon Wea Rev 134:1299-1315
Chou M-D, Suarez MJ (1999) A solar radiation parameterization for atmospheric studies 15:38. NASA/TM-1999-104606

Chou M-D, Suarez MJ, Tsay S-C, Fu Q (1999) Parameterization for cloud longwave scattering for use in atmospheric models. J Clim 12:159-169

Chou M-D, Suarez MJ, Lee K-T (2005) A parameterization of the effective layer emission for infrared radiation calculation. J Atmos Sci 62:531-541

Chun H-Y, Baik J-J (1998) Momentum flux by thermally induced internal gravity waves and its approximation for large-scale models. J Atmos Sci 55:3299-3310

Covey C, AchutaRao KM, Cubasch U, Jones P, Lambert SJ, Mann ME, Phillips TJ, Taylor KE (2003) An overview of results from the coupled model intercomparison project. Glob Planet Change 37:103-133

Dai A (2006) Precipitation characteristics in eighteen coupled climate models. J Clim 19:4605-4630

Danabasoglu G et al (2006) Diurnal coupling in the tropical oceans of CCSM3. J Clim 19:2347-2365

Fu X, Wang B, Li T, McCreary JP (2003) Coupling between northward-propagating, intraseasonal oscillation and sea surface temperature in the Indian Ocean. J Atmos Sci 60:1733-1753

Fu X, Wang B, Li T, McCreary JP (2004) Differences of boreal summer intraseasonal oscillations simulated in an atmosphereocean coupled model and an atmosphere-only model. J Clim $17: 1263-1271$

Fu X, Wang B, Li T, Wang B, Waliser DE, Tao L (2007) Impact of atmosphere-ocean coupling on the predictability of monsoon intraseasonal oscillation. J Atmos Sci 64:157-174

Ham S, Hong S-Y (2013) Sensitivity of simulated intraseasonal oscillation to four convective parameterization schemes in a coupled climate model. Asia-Pacific J. Atmos. Sci. in press

Ham Y-G, Kug J-S, Kang I-S, Jin F-F, Timmerman A (2010) Impact of diurnal atmosphere-ocean coupling on the tropical climate simulations using a coupled GCM. Clim Dyn 34:905-917

Hayashi Y (1979) A generalized method of resolving transient disturbances into standing and traveling waves by space-time spectral analysis. J Atmos Sci 36:1017-1029

Hendon HH (2000) Impact of air-sea coupling on the Madden-Julian oscillation in a general circulation model. J Atmos Sci 57:3939-3952

Hong S-Y, Pan H-L (1998) Convective trigger function for mass flux cumulus parameterization scheme. Mon Wea Rev 126:2599 2620

Hong S-Y, Chang E-C (2012) Spectral nudging sensitivity experiments in a regional climate model. Asia-Pacific J Atmos Sci 48:345-355

Hong S-Y, Juang H-MH, Zhao Q (1998) Implementation of prognostic cloud scheme for a regional spectral model. Mon Wea Rev 126:2621-2639

Hong S-Y, Noh Y, Dudhia J (2006) A new vertical diffusion package with an explicit treatment of entrainment processes. Mon Wea Rev 134:2318-2341

Hong S-Y, Park H, Cheong H-B, Kim J-E, Koo M-S, Jang J, Ham S, Hwang S-O, Park B-K, Chang E-C, Li H (2013) The global/ regional integrated model system (GRIMs). Asia Pacific J Atmos Sci 49(2):219-243

Hoyos CD, Webster PJ (2007) The role of intraseasonal variability in the nature of Asian monsoon precipitation. J Clim 20:4402-4424

Huffman GJ, Adler RF, Morrissey M, Bolvin DT, Curtis S, Joyce R, McGavock B, Susskind J (2001) Global precipitation at onedegree daily resolution from multisatellite observations. J Hydrometeorol 2:36-50

Inness PM, Slingo JM, Guilyardi E, Cole J (2003) Simulation of the Madden-Julian oscillation in a coupled general circulation model. Part II: the role of the basic state. J Clim 16:365-382 
Jeon J-H, Hong S-Y, Chun H-Y, Song I-S (2010) Test of a convectively forced gravity wave drag parameterization in a general circulation model. Asia-Pacific J Atmos Sci 46:1-10

Kanamitsu M, Ebisuzaki W, Woollen J, Yang S-K, Hnilo JJ, Fiorino M, Potter GL (2002) NCEP-DOE AMIP-\#Reanalysis (R-2). Bull Am Meteorol Soc 83:1631-1643

Kang I-S, Ho CH, Lim YK (1999) Principal modes of climatological seasonal and intraseasonal variations of the Asian summer monsoon. Mon Wea Rev 127:322-340

Kara AB, Rochford PA, Hurlburt HE (2003) Mixed layer depth variability over the global ocean. J Geophys Res 108(C3):3079. doi:10.1029/2000JC000736

Kim Y-J, Arakawa A (1995) Improvement of orographic gravity wave parameterization using a mesoscale gravity wave model. J Atmos Sci 52:1875-1902

Kim E-J, Hong S-Y (2010) Impact of air-sea interaction on East Asian summer monsoon climate in WRF. J Geophys Res 115:D19118. doi:10.1029/2009JD013253

Kim H-M, Kang I-S (2008) The impact of ocean-atmosphere coupling on the predictability of boreal summer intraseasonal oscillation. Clim Dyn 31:859-870

Kim D et al (2009) Application of MJO simulation diagnostics to climate models. J Clim 22:6413-6436

Kim H-M, Hoyos CD, Webster PJ, Kang I-S (2010) Oceanatmosphere coupling and the boreal winter MJO. Clim Dyn 35:771-784

Klingaman NP, Woolnoug SJ, Weller H, Slingo JM (2011) The impact of finer-resolution air-sea coupling on the intraseasonal oscillation of the Indian monsson. J Clim 24:2451-2468

Kug J-S, Kang I-S, Choi D-H (2008) Seasonal climate predictability with tier-one and tier-two prediction systems. Clim Dyn 31:403-416

Kumar OSRUB, Rao SR, Ranganathan S, Raju SS (2010) Role of intra-seasonal oscillations on monsoon floods and droughts over India. Asia Pacific J Atmos Sci 46:21-28

Lau K-M, Chan PH (1986) Aspects of the 40-50 day oscillation during the northern summer as inferred from outgoing longwave radiation. Mon Wea Rev 114:1354-1367

Lawrence DM, Webster PJ (2002) The boreal summer intraseasonal oscillation: relationship between northward and eastward movement of convection. J Atmos Sci 59:1593-1606

Lin J-L et al (2006) Tropical intraseasonal variability in 14 IPCC AR4 climate models. Part I convective signals. J Clim 19:2665-2690

Lin J-L et al (2007) The double-ITCZ problem in IPCC AR \$ coupled GCMs: ocean-atmosphere feedback analysis. J Clim 20:44974525

Madden RA, Julian PR (1971) Detection of a 40-50 day oscillation in the zonal wind in the tropical Pacific. J Atmos Sci 28:702-708

Madden RA, Julian PR (1994) Observations of the 40-50-day tropical oscillation. A review. Mon Wea Rev 122:814-837

Murakami T, Nakazawa T (1985) Tropical 45 day oscillations during the 1979 northern hemisphere summer. J Atmos Sci 42:1107-1122

Newman M (2007) Interannual to decadal predictability of tropical and north Pacific sea surface temperature. J Clim 20:2333-2356

Oh J-H, Kim B-M, Kim K-Y, Song H-J, Lim G-H (2013) The impact of the diurnal cycle on the MJO over the Maritime Continent: a modeling study assimilating TRMM rain rate into global analysis. Clim Dyn 40:893-911

Pacanowski RC, Griffies SM (1998) MOM 3.0 manual. NOAA/ Geophysical Fluid Dynamics Laboratory, Princeton, p 668

Pan H-L, Wu W-S (1995) Implementing a mass flux convective parameterization package for the NMC medium-range forecast model. In: NMC Office Note 409, NCEP/EMC, Camp Springs, Md, pp 40

Park H, Hong S-Y (2007) An evaluation of a mass-flux cumulus parameterization scheme in the KMA Global Forecast System. J Meteor Soc Japan 85(2):151-169
Park S, Hong S-Y, Byun Y-H (2010) Precipitation in boreal summer simulated by a GCM with two convective parameterization scheme: implications of the intraseasonal oscillation for dynamic seasonal prediction. J Clim 23:2801-2816

Pegion K, Kirtman BP (2008) The impact of air-sea interactions on the predictability of the tropical intraseasonal oscillation. J Clim 21:5870-5886

Rajendran K, Kitoh A (2006) Modulation of tropical intraseasonal oscillations by ocean-atmosphere coupling. J Clim 19:366-391

Reynolds RW, Smith TM (1994) Improved global sea surface temperature analysis using optimum interpolation. J Clim 7:929-948

Seo K-H, Wang W (2010) The Madden-Julian oscillation simulated in the NCEP climate forecast system model: the importance of stratiform heating. J Clim 23:4770-4793

Skamarock WC (2008) A description of the advanced research WRF version 3. NCAR Tech Note NCAR/TN-475 + STR, pp 113

Slingo JM et al (1996) Intraseasonal oscillation in 15 atmospheric general circulation models. Results from an AMIP diagnostic subproject. Clim Dyn 12:325-357

Sperber KR, Annamalai H (2008) Coupled model simulations of boreal summer intraseasonal (30-50 day) variability, part I: systematic errors and caution on use of metrics. Clim Dyn 31:345-372

Srinivasan J, Smith GL (1996) Meridional migration of tropical convergence zones. J Appl Meteorol 35:1189-1202

Waliser DE et al (2009) MJO simulation diagnostics. J Clim 22:30063030

Watterson IG (2013) Climate change simulated by full and mixedlayer ocean versions of CSIRO Mk3.5 and Mk3.0: The AsiaPacific region. Asia-Pacific J Atmos Sci 49(3):287-300

Watterson IG, O'Farrell SP (2013) Climate change simulated by full and mixed-layer ocean versions of CSIRO Mk3.5 and Mk3.0: Large-scale sensitivity. Asia-Pacific J Atmos Sci 49(3):375-387

Weaver SJ, Wang W, Chen M, Kumar A (2011) Representation of MJO variability in the NCEP climate forecast system. J Clim 24:4476-4694

Wheeler MC, Hendon HH (2004) An all-season real-time multivariate MJO index: development of an index for monitoring and prediction. Mon Wea Rev 132:1917-1932

Woolnough SJ, Vitart F, Balmaseda MA (2007) The role of the ocean in the Madden-Julian oscillations for MJO prediction. Q J R Meteorol Soc 109:2961-3012

Wu R, Kirtman BP, Pigion K (2007) Surface latent heat flux and its relationship with sea surface temperature in the National Centers for Environmental Prediction Climate Forecast System simulations and retrospective forecasts. Geophys Res Lett 34:L17712. doi:10.1029/2007GL030751

Xie P, Arkin PA (1997) Global precipitation: a 17-year monthly analysis based on gauge observations, satellite estimates, and numerical model outputs. Bull Am Meteor Soc 78:2539-2558

Yasunari T (1981) Structure of an Indian summer monsoon system with around 40-day period. J Meteor Soc Japan 59:336-354

Yu L, Weller RA, Sun B (2004) Improving latent and sensible heat flux estimates for the Atlantic Ocean (1988-1999) by a synthesis approach. J Clim 17:373-393

Zhang C (2005) Madden-Julian oscillation. Rev Geophys 43:RG2003. doi:10.1029/2004RG000158

Zhang C, Gottschalck J (2002) SST anomalies of ENSO and the Madden-Julian oscillation in the equatorial Pacific. J Clim 15:2429-2445

Zhang C, Dong M, Gualdi S, Hendon HH, Maloney ED, Marshall A, Sperber KR, Wang W (2006) Simulations of the Madden-Julian oscillation in four pairs of coupled and uncoupled global models. Clim Dyn 27:573-592

Zheng Y, Waliser DE, Stern WF, Jones C (2004) The role of coupled sea surface temperatures in the simulation of the tropical intraseasonal oscillation. J Clim 17:4109-4134 